\title{
Location-based transport demand forecasting methods for suburbanized areas
}

\author{
Anton Zedgenizov \\ Department of Motor Transport \\ Irkutsk State Technical University \\ Russia \\ azedgen@gmail.com
}

\begin{abstract}
The article deals with the issue of transport accessibility in agglomerations, large cities and adjacent areas. Examples of individual and public transport speed effects on suburban boundaries are provided. Data on transport accessibility of Irkutsk agglomeration consisting of suburbanized areas of different land-use forms are provided. Dependences reflecting the volumes of generating capacities of suburbanized areas are determined. Examples of Paris agglomeration transportation management are provided. Generating capacities of suburbanized areas are calculated and compared with real transport intensity parameters in agglomeration areas. Recommendations of practical application of empirical dependences are suggested.
\end{abstract}

Keywords - agglomeration; transport accessibility; traffic generation; traffic intensity; suburbanization.

\section{INTRODUCTION}

Transport is one of the most important and complex industries. It is closely connected with technology development, urban planning policies and social and demographic development of cities and countries. Reasonable transport decisions contribute to development of cities, neighbor areas and large industries, quality and full satisfaction of cultural and community needs.

Agglomerations which have existed for a long time allow the use of resources of neighbor areas [6, 7, 8, 12, 13]. Resources are seen as capacities of transport infrastructure, utility systems, working areas, and cultural and community areas. Urban space saving ideas are significant since the expansion of urban boundaries increases transportation speed rates and encourages application of new high-speed transport modes which is not always reasonable, particularly in areas with low population density. Moreover, the use of personal transport increases the size of areas occupied by transport facilities (roads, parking areas, interchanges, etc.). On the contrary, the use of public transport (about 75-80\%) decreases the share of urban areas occupied by transport facilities up to $20-25 \%$, and the use of the underground system - up to $15 \%$ $[10,2]$

\section{METHODS AND MATERIALS}

Currently, agglomeration processes are key tools of national and regional development improving living standards, creating comfortable conditions and raising competitive capacities of Russia as an integral whole connected with a settlement system skeleton and transport and energy facilities focused on an innovation development scenario. The need for agglomeration development is conditioned by exhaustion of production and infrastructure areas and expansion of urban areas. Development of agglomerations can solve these issues.

Agglomerations increase traffic distances, so higher transportation speed rates and reduced time expenditure are required. Mean personal transport speed rates in large cities vary between 18 and $26 \mathrm{~km}$ per hour. In agglomeration areas, speed rates can increase up to 33-35 km per hour. Mean public transport speed rates are about 14 and $17 \mathrm{~km}$ per hour. Therefore, boundaries of real agglomerations are limited by transport infrastructure capacities aimed to ensure transportation speed rates complying with existing travel time values [3]. For example, in Irkutsk (600 thousand residents), one-way travel takes 37 minutes for $85-90 \%$ of city residents. In cities with population exceeding one million people, one-way travel time takes 45 minutes. In capital cities, travel time standards are different.

Real agglomeration boundaries of Irkutsk and neighbor areas can be determined with regard to time expenditure within 26\% (for personal transport) and 37\% (for public transport) of total travel time expenditure at mean speed rates of 33 and $16 \mathrm{~km}$ per hour respectively. Thus, real agglomeration boundaries will be $16 \mathrm{~km}$ for personal transport and 8 $\mathrm{km}$ for public transport (Fig. 1). Most villa communities locating outside the city (Molodezhny, Zapadny, Izumrudny, etc.), gardeners' communities which are used for permanent residence (Melnichnaya Pad), large rural settlements (Dzerzhinsk, Pivovarikha, Mamony, Smolenshchina, etc.), a satellite town Shelekhov will be included in the agglomeration. Angarsk, one more satellite town, does not have any stable labor relations with Irkutsk.

Public transport accessibility is twice less than personal transport accessibility due to low travel speed rates. Mort Irkutsk districts are located within public transport accessibility areas. Novo-Lenino and Irkutsk-2 are exceptions. Thus, it is reasonable to use different transport means depending on travel distances. Recommendations should be individual for each city, however there are some universal ones for large urban areas: 
City centers are environment where pedestrians rather than cars, public transport vehicles rather than personal ones are priorities. Personal transport vehicles can be used if public transport is inaccessible.

Within the city limits, public transport takes priority over personal one. Personal transport vehicles and pedestrians are equal.

In suburban areas, towns and urban-type settlements, personal transport vehicles are more important than public transport means.

The last statement is based on low population density (1520 ha) in comparison with 50-60 hectares in large cities and 300 hectares in densely populated areas which increases the need for personal transport vehicles and leads to traffic jams and deficient parking facilities.

\section{RESULTS}

In reality, it is impossible to differentiate the application of transport vehicles by this zoning criterion since people can travel from suburban areas to the city center. For example, $90 \%$ of people use personal transport vehicles for travelling from suburban areas located at a distance of 10-15 kilometers from the city center [5]. Development of park and ride $(\mathrm{P}+\mathrm{R}$, Park\&Ride) facilities which are widespread in Europe can encourage the use of public transport means. Measures aimed to encourage the use of public transport means in urban areas and particularly in city centers have to be taken to decrease traffic intensity in agglomeration areas during peak hours.

Due to limited travel speed rates, agglomeration relations are strong at a distance of $15-20 \mathrm{~km}$. They become weaker at a distance of 25-30 km. The author of [1] has drawn the same conclusions. At a distance of $50 \mathrm{~km}$, relations between cities and towns are insignificant. One of the striking examples of extended agglomeration boundaries is the Paris agglomeration with a radius of $70 \mathrm{~km}$. This radius is ensured by high-speed trains which travel with a speed of $250-300 \mathrm{~km}$ per hour. Thus, agglomeration measures can consolidate urban planning and transport industries, labor markets and sales markets, including energy outlets, and develop ecological optimum decisions.

The analysis of data on Irkutsk suburban areas accounting for generating capacities of MAC-type areas helps calculate and determine empirical dependences for predicting traffic intensity in agglomeration areas. Road network loads can be predicted for the dead-end Melnichny direction. The research [4] argues that the area of gardeners' non-commercial partnerships (GNPs) can generate about 9 - 14 travels per hectare of the MAC-type area. With regard to significant sizes of developed suburban areas (about 3000 ha) in each direction, traffic intensity can turn agglomeration areas into areas of permanent and mass traffic jams. Even approximate calculations show that traffic intensity during peak hours can be $1500-2000$ cars per hour [9]. Both the size of MAC-type areas and their distances from the city center should be taken into account when predicting traffic intensity since this fac-tor is important for daily labor travels.

The regression analysis shows that the empirical dependence meets stastistical criteria $(\mathrm{R} 2=0,95 ; \mathrm{F} 95 \% ; 1 ; 6=$ $80,75 ; \mathrm{t} 95 \% ; 5=12,6)$. The relations of the amount of travels, distances from the city center and GNP areas are shown in
Figure 3. The dependece is presented as a plane whose slope relative to the axis of distances from the city center is insignificant.

In reality, it is impossible to differentiate the application of transport vehicles by this zoning criterion since people can travel from suburban areas to the city center. For example, $90 \%$ of people use personal transport vehicles for travelling from suburban areas located at a distance of 10-15 kilometers from the city center [5]. Development of park and ride ( $\mathrm{P}+\mathrm{R}$, Park\&Ride) facilities which are widespread in Europe can encourage the use of public transport means. Measures aimed to encourage the use of public transport means in urban areas and particularly in city centers have to be taken to decrease traffic intensity in agglomeration areas during peak hours.

Due to limited travel speed rates, agglomeration relations are strong at a distance of $15-20 \mathrm{~km}$. They become weaker at a distance of 25-30 km. The author of [1] has drawn the same conclusions. At a distance of $50 \mathrm{~km}$, relations between cities and towns are insignificant. One of the striking examples of extended agglomeration boundaries is the Paris agglomeration with a radius of $70 \mathrm{~km}$. This radius is ensured by high-speed trains which travel with a speed of $250-300 \mathrm{~km}$ per hour. Thus, agglomeration measures can consolidate urban planning and transport industries, labor markets and sales markets, including energy outlets, and develop ecological optimum decisions.

The analysis of data on Irkutsk suburban areas accounting for generating capacities of MAC-type areas helps calculate and determine empirical dependences for predicting traffic intensity in agglomeration areas. Road network loads can be predicted for the dead-end Melnichny direction. The research [4] argues that the area of gardeners' non-commercial partnerships (GNPs) can generate about 9 - 14 travels per hectare of the MAC-type area. With regard to significant sizes of developed suburban areas (about 3000 ha) in each direction, traffic intensity can turn agglomeration areas into areas of permanent and mass traffic jams. Even approximate calculations show that traffic intensity during peak hours can be $1500-2000$ cars per hour [9]. Both the size of MAC-type areas and their distances from the city center should be taken into account when predicting traffic intensity since this factor is important for daily labor travels.

The regression analysis shows that the empirical dependence meets statistical criteria $\left(\mathrm{R}^{2}=0,95 ; ; \mathrm{F}_{95 \% 1 ; 6}=\right.$ 80,$\left.75 ; t_{95 \% 5}=12,6\right)$. The relations of the amount of travels, distances from the city center and GNP areas are shown in Figure 3. The dependence is presented as a plane whose slope relative to the axis of distances from the city center is insignificant.

Thus, a daily amount of travels to GNPs can be calculated by formula:

$$
\mathrm{E}_{16}=7,069 \cdot \mathrm{S}_{16},
$$

where $\mathrm{S} 16$ is the GNP area, hectare.

From equation (1), it follows that 1 hectare of a MAC-type area generates about 7 persons. Equation (1) is true for the period from May to October. Researches carried out in February show that the distance from the city center is the most significant factor. On the other hand, during working periods when people travel to and from work on a daily basis, 
the distance from the city center is a key factor. For example, the specific amount of travels from Electron GNP located at a distance of $12 \mathrm{~km}$ from the city center is 3,4 persons per hectare, while from Podsnezhnik GNP located at a distance of $16 \mathrm{~km}$, it is 1,4 persons per hectare. The specific amount of travels from Dorozhny stroitel GNP located at a distance of 20 $\mathrm{km}$ is 0,4 persons per hectare. The dependence can be determined as:

$$
\mathrm{G}=7,73-0,375 \cdot \mathrm{L}
$$

where $G$ is the specific generation of travels, persons per hectare; L is the distance from the city center, km. From equation (2), it follows that the minimum distance from the city center is $7,73 \mathrm{~km}$, and the maximum one is $20,6 \mathrm{~km}$ which decreases the specific generation value by 0,52 persons per hectare with each kilometer.

Equations (1) and (2) can be used to predict traffic intensity, including for the Melnichny Pad direction. It is known that the total area of GNPs in this direction is 3002 hectares. Therefore, the amount of daily travels by (1) is $\mathrm{Y}=7,069 \cdot 3002=21221$ travels per day. If the mean amount of people traveling by PT is 0,78 , the mean number of PT passengers is 1,73 per car, and the daily maximum ratio is 0,103 , then we have 9576 cars per day and the peak intensity value is 986 cars per hour $[11,14,15]$. Figure 3 shows the results of the equation test and calculations.

Calculations and field measurements coincide (the deviation value is less than $5 \%$ by daily traffic intensity and less than $10 \%$ by hour traffic intensity). Using the suggested empirical dependences and reference data on MAC-type areas, current and future traffic intensity and road network loads can be predicted. The author argues that RMSE-based comparison of daily inequality ratios can identify similarities of GNPs and urban residential districts (Fig. 5). The analysis shows that arrival ratios are similar $\left(\mathrm{R}^{2}=0,67\right)$ while departure ones are different. Residents of both GNPs and RDs head home after working hours, while the departure peak for GNPs falls on evening hours when some residents go to their residential districts (apartments).

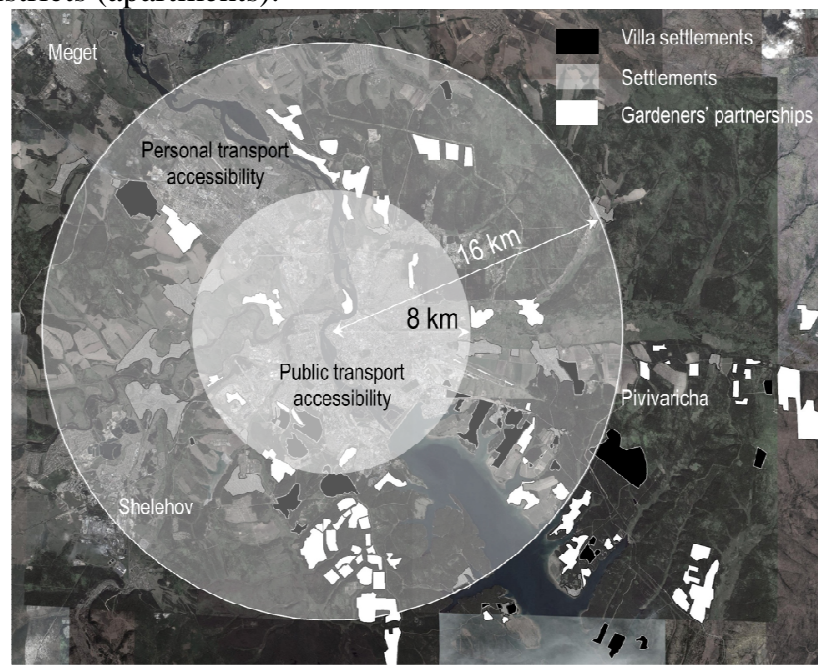

Fig. 1. Agglomeration boundaries of Irkutsk and its neighbor areas

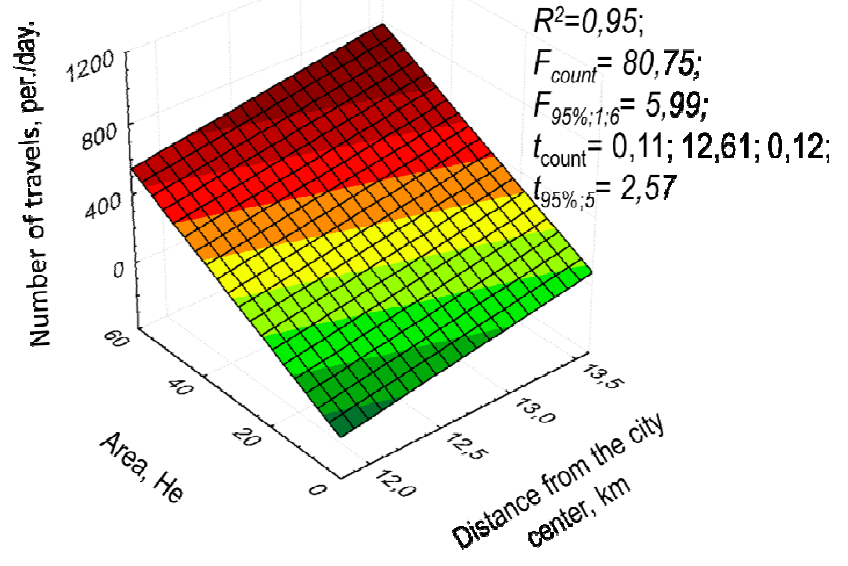

Fig. 2. Relations of the amount of travels, GNP areas and distances from the city center/

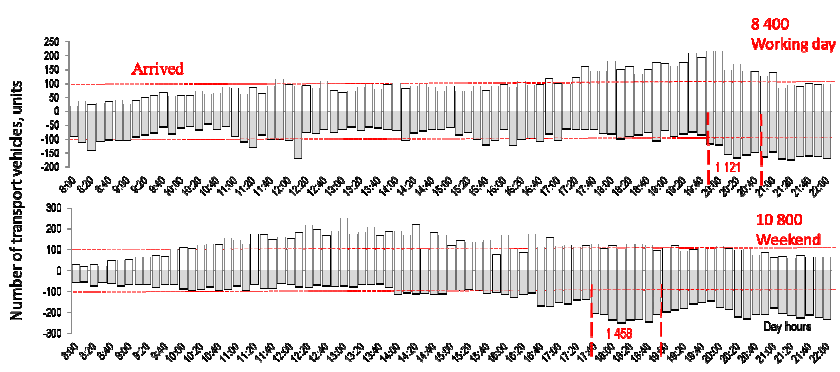

Fig. 3. Field measurement of traffic intensity
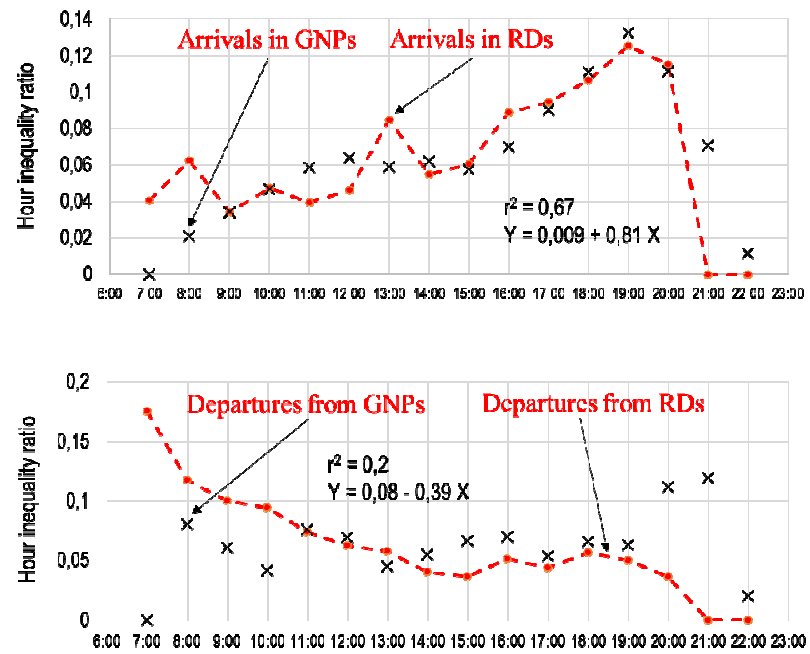

Fig. 4. RMSE-based analysis of daily inequality ratios for GNPs and urban residential districts $(\mathrm{RD})$ by arrivals and departures

\section{CONCLUSION}

To conclude, it should be noted that further suburbanization studies need to take into account a variety of other factors (e.g., material well-being, road network 
development, alternative transport systems, suburban trains, etc.).

\section{References}

[1] L.F. Buchev, Planning structure of group systems of settlements in intensive industrialized areas. Author's abstract. Moscow, 1976.

[2] Vukan R. Vuchik, Transport in comfortable cities: Territory of the future, Moscow, 2011.

[3] A.V. Gorodkov, Fundamentals of territorial development of cities, Bryansk: BGITA, 2009.

[4] A.V. Zedgenizov, Suburbanization of Irkutsk city: levels and results. Proceedings of universities. Investment, Construction. Real Estate, Vol. 1, pp. 159-165, 2016.

[5] A. Siegel, D. Wolf, Models of group behavior in the "human-machine" system, Moscow: Mir, 1973.

[6] E.M. Lobanov, Transport planning of cities, Moscow: Transport, 1990.

[7] Guidelines for urban reconstruction, Administrative city centers. Moscow: Stroyizdat, 1979.

[8] A.V. Sigaev, Planning and transport issues of urban agglomerations, Moscow: Stroyizdat, 1978.
[9] V.V. Silyanov, Theory of transport flows in road designing and traffic management, Moscow: Transport, 1977.

[10] CRR 2.07.01-89*. Urbanization. Planning and development of urban and rural settlements, The State Committee for Construction of the USSR. Moscow: CRR of the State Committee for Construction of the USSR, 1989.

[11] K. Goulias, R. Pendylala, R. Kitamura, "Practical Method for the Estimation of Trip Generation and Trip Chaining", Transportation Research Record 1285, Transportation Research Board, Washington, DC, 1990.

[12] S. Hanson, J. Huf£ "Classification Issues in the Analysis of Complex Travel Behavior," Economic Geography, Vol. 57, pp. 332-347, 1987.

[13] A.V. Sohoni, M. Thomas, K.V.K. Rao "Application of the concept of transit oriented development to a suburban neighborhood," Transportation Research Procedia, Vol. 25, pp. 3224-3236, 2017.

[14] Trip Generation, 8th Edition. Washington, DC: Institute of Transportation Engineers (ITE), 2008.

[15] A.V. Zedgenizov, D.G. Burkov, Methods for the Traffic Demand Assessment Based on the Quantitative Characteristics of Urban Areas Functioning. 12th International Conference "Organization and Traffic Safety Management in large cities", SPbOTSIC-2016, 28-30 September 2016, St. Petersburg, Russia. Edited by Ulrich Brannolte, Pavel Pribyl and Valentin Silyanov. Transportation research procedia, pp. 724-730, 2016. 